\title{
QUANTIDADE DE NUTRIENTES EXTRAÍDOS PELA GRAMA BERMUDA EM FUNÇÃO DE DOSES DE NITROGÊNIO
}

\author{
NUTRIENTS QUANTITIES EXTRACTED BY BERMUDA GRASS IN FUNCTION OF \\ NITROGEN DOSES
}

\section{Claudinei Paulo de LIMA ${ }^{1}$; Clarice BACKES ${ }^{2}$; Alessandro José Marques SANTOS ${ }^{2}$; Dirceu Maximino FERNANDES ${ }^{3}$; Roberto Lyra VILLAS BÔAS ${ }^{4}$; Mauricio Roberto de OLIVEIRA ${ }^{5}$}

1. Engenheiro Agrônomo, Professor, Doutor, Faculdades Integradas de Ourinhos - FIO e Faculdade de Tecnologia de Ourinhos FATEC, Ourinhos, SP, Brasil. neiagro@ yahoo.com.br; 2. Engenheiro(a) Agrônomo(a), Professor(a), Dr(a)., Universidade Estadual do Goiás, São Luís dos Montes Belos, GO, Brasil; 3. Engenheiro Agrônomo, Professor Doutor, Faculdade de Ciências Agronômicas FCA, Universidade Estadual Paulista - UNESP, Departamento de Solos e Recursos Naturais, Botucatu, SP, Brasil; 4. Engenheiro Agrônomo, Professor Titular, FCA/UNESP, Departamento de Solos e Recursos Naturais, Botucatu, SP, Brasil; 5. Engenheiro Agrônomo, Doutorando em Agronomia, Agricultura -FCA/UNESP, Botucatu, SP, Brasil.

RESUMO: O nitrogênio proporciona as maiores respostas no crescimento das gramas. Objetivou-se com este trabalho avaliar a extração total de macronutrientes pela grama bermuda em função de doses de nitrogênio. O experimento foi conduzido em propriedade de grama, localizada na cidade de Capela do Alto - SP. O delineamento experimental utilizado foi o de blocos ao acaso, com cinco tratamentos e quatro repetições. Os tratamentos foram constituídos por cinco doses de $\mathrm{N}$ : $0,150,300,450$ e $600 \mathrm{~kg} \mathrm{ha}^{-1}$. Após cada corte da grama foram coletadas as aparas determinando-se a matéria seca e a concentração de macronutrientes. Com a colheita dos tapetes, determinou-se a matéria seca extraída com a retirada do mesmo e a concentração de nutrientes. A quantidade de macronutrientes extraídos foi calculada através do produto da massa seca pela concentração dos mesmos. Com a retirada das aparas cortadas durante o ciclo houve grande extração de nutrientes, 204; 18; 101; 22; 10 e $27 \mathrm{~kg} \mathrm{ha}^{-1}$ para N, P, K, Ca, Mg e S, respectivamente. As quantidades de nutrientes necessárias para promover $100 \%$ de cobertura do solo pela grama são de 219,$5 ; 27 ; 174,1 ; 31,8 ; 13,4 ;$ e $39,9 \mathrm{~kg}^{-1} \mathrm{de} \mathrm{N}$, $\mathrm{P}, \mathrm{K}, \mathrm{Ca}, \mathrm{Mg}$ e S, respectivamente.

PALAVRAS-CHAVE: Cynodon dactylon. Adubação. Aparas. Extração.

\section{INTRODUÇÃO}

A crescente demanda e maior exigência do mercado consumidor, quanto a qualidade final dos gramados, são os dois principais fatores que impulsionam as áreas produtoras, principalmente próximas dos grandes pólos consumidores. Dentre outros fatores de expansão, inclui-se o desenvolvimento de novas variedades, o lançamento de produtos e máquinas específicas para utilização em gramas, a adaptação e aperfeiçoamento das técnicas de produção, implantação e manutenção de gramados, e principalmente a adubação (GODOY, 2005).

As gramas, como qualquer outra cultura, necessitam de nutrientes em qualidade e quantidades corretas para se apresentarem com sua plena exuberância, necessitando assim de todos os nutrientes essenciais para o seu desenvolvimento. Essa demanda de nutrientes pode variar conforme a espécie e os cultivares.

Considerando apenas as espécies de verão que são utilizadas no Brasil têm-se algumas diferenças em relação à demanda nutricional, onde a grama bermuda e a bermuda híbrida são mais exigentes que as demais, pela elevada taxa de crescimento que apresentam (GODOY; VILLAS BÔAS, 2003).

Ao classificar os gramados quanto à exigência nutricional, as áreas de produção de tapetes de grama podem ser consideradas de alta exigência, pois além das aparas (clippings) cortadas durante o ciclo de produção, o tapete é retirado da área levando todos os nutrientes absorvidos, além dos nutrientes contidos no solo que é levado juntamente com o tapete (BACKES; LIMA, 2008).

Segundo Bowman et al. (2002), o nitrogênio é o elemento mineral requerido em maiores quantidades pelas gramas, no entanto, a quantidade de $\mathrm{N}$ disponível na maioria dos solos é insuficiente para atender uma alta exigência do gramado e, portanto, aplicações regulares de fertilizante nitrogenado são necessárias. A qualidade ótima de um gramado requer um programa intensivo de adubação nitrogenada com altas doses (EXNER et al. 1991; QUIROGA-GARZA et al. 2001).

Doses elevadas de $\mathrm{N}$ e maior frequência de aplicação podem reduzir o tempo de produção da grama, entretanto, doses excessivas forçam o crescimento da parte aérea em detrimento do 
sistema radicular, reduzindo, pela menor quantidade de raízes, estolões e rizomas, a capacidade do tapete de ser manuseado após o corte ("liftalility") (CHRISTIANS, 1998; CARROW et al. 2001). Esse maior crescimento da parte aérea das gramas proporcionada por doses excessivas de $\mathrm{N}$ é indesejável por causa do corte mais frequente requerido, causando aumento dos custos de produção (QUIROGA-GARZA et al. 2001). Juntamente com as aparas são retiradas do sistema parte dos nutrientes aplicados que segundo Bowman et al. (2002) é uma perda a ser considerada.

De acordo com Carrow et al. (2001), a remoção ou não das aparas pode influenciar no ajuste da dose de $\mathrm{N}$ para gramados. A quantidade de nutrientes extraída de um gramado pode ser estimada pela quantidade de nutriente que é removida com as aparas retiradas após o corte (GODOY; VILLAS BÔAS, 2003). No sistema de produção de gramas a quantidade total de nutrientes acumuladas pela planta também pode dar uma ideia da quantidade a ser reposta no próximo ciclo, após a exportação dos nutrientes com a colheita do tapete (GODOY, 2005).

No Brasil, não existem valores de referência da extração de nutrientes pela grama bermuda. $\mathrm{O}$ conhecimento da extração de nutrientes pela grama pode possibilitar o entendimento de fatores relacionados à nutrição mineral da cultura e consequentemente permitir calibrar as doses de adubos para cada espécie.

Objetivou-se com este trabalho avaliar a extração de macronutrientes pela grama bermuda, em função da aplicação de doses de nitrogênio na superfície do solo, em sistema de produção de tapetes de grama.

\section{MATERIAL E MÉTODOS}

O experimento foi instalado em área de produção comercial de grama bermuda, no município de Capela do Alto-SP, localizada nas coordenadas geográficas $23^{\circ} 91^{\prime}$ de latitude sul e $48^{\circ} 03^{\prime}$ de longitude oeste de Greenwich e altitude média de $636 \mathrm{~m}$.

O solo é classificado como Latossolo Vermelho distrófico, de textura média conforme nomenclatura do Sistema Brasileiro de Classificação de Solos (EMBRAPA, 2006). De acordo com o resultado da análise, o solo possuía as seguintes características químicas antes da instalação do experimento $\mathrm{pH}\left(\mathrm{CaCl}_{2}\right)$ de 4,$8 ; 18 \mathrm{~g} \mathrm{dm}^{-3}$ de M.O.; $26 \mathrm{mg} \mathrm{dm}^{-3}$ de $\mathrm{P}$ (resina); 37; 1,6; 16 e 8 mmol $_{\mathrm{c}} \mathrm{dm}^{-3}$ de $\mathrm{H}^{+}+\mathrm{Al}^{+3}, \mathrm{~K}, \mathrm{Ca}$ e $\mathrm{Mg}$, respectivamente; $\mathrm{V}$ de $41 \%$.
A calagem foi realizada na área total, aplicando-se sobre a superfície do solo, $0,70 \mathrm{Mg}^{-}$ 1 de calcário dolomítico (PRNT de 91\%) considerando a saturação por bases desejada igual a $60 \%$.

A espécie utilizada foi a grama bermuda Cynodon dactylon [Pers] L., variedade Celebration, é rizomatosa e, portanto, pode ser colhida em área total, visto que após a colheita ficam rizomas subsuperficiais capazes de brotarem e cobrir novamente o solo. Esta variedade também possui um vigoroso sistema radicular, o que lhe confere um rápido crescimento na produção (fazenda) e uma rápida recuperação a danos mecânicos causados por tacos de golfe, tráfego de máquinas e implementos e por pisoteio. Também possui uma tolerância moderada ao sombreamento, o que é incomum para uma grama desse gênero.

Aos trinta dias após a calagem foi realizada a adubação fosfatada, adicionando-se $80 \mathrm{~kg} \mathrm{ha}^{-1}$ de $\mathrm{P}_{2} \mathrm{O}_{5}$, tendo como fonte o superfosfato triplo.

$\mathrm{O}$ delineamento experimental utilizado foi em blocos casualizados, com cinco tratamentos e quatro repetições. Os tratamentos foram constituídos de cinco doses de nitrogênio: 0, 150, 300, 450 e 600 $\mathrm{kg} \mathrm{ha}^{-1}$, na forma de ureia, que foram parceladas aos 40, 89 e 124 dias após o corte do tapete anterior (DAC). As parcelas experimentais tinham 5,0 x $2,5 \mathrm{~m}$ com $0,5 \mathrm{~m}$ de cada extremidade como bordadura.

A adubação potássica na dose de $200 \mathrm{~kg} \mathrm{ha}^{-1}$ de $\mathrm{K}_{2} \mathrm{O}$, usando como fonte cloreto de potássio, também foi parcelada em três vezes na mesma época da adubação nitrogenada. Não foi utilizada nenhuma fonte mineral de enxofre.

A grama foi mantida a uma altura aproximada de $2,5 \mathrm{~cm}$, sendo o corte realizado conforme a necessidade, utilizando-se uma roçadeira à gasolina com coletor recolhendo as aparas ("clipping") para determinação da fitomassa seca. Os cortes foram removidos e amostrados em quatro épocas (nov/07, dez/07, jan/08 e fev/08) para todos os tratamentos.

Os pesos frescos dos cortes para cada parcela foram mensurados e uma amostra aleatória foi removida e pesada antes e após a secagem. As amostras foram secas em estufa de circulação e renovação de ar forçada por 72 horas na temperatura de $65^{\circ} \mathrm{C}$. Após esse período determinou-se a massa da matéria seca da amostra e por regra de três obteve-se a quantidade de massa seca total coletada na parcela. A quantidade de material coletado em cada data foi somada durante o ciclo, obtendo-se o total de aparas retirada do local. Coletou-se uma amostra para a determinação da concentração de 
nutrientes de acordo com a metodologia modificada de Malavolta et al. (1997). A extração de nutrientes pelas aparas foi obtida através do produto da quantidade de nutrientes contidos nas aparas pela massa da matéria seca coletada.

A taxa de cobertura do solo pela grama foi avaliada através da análise de imagem digital, aos 161 (fevereiro) dias após o corte do tapete anterior. As imagens digitais foram obtidas de uma câmera digital Sony DSC-W30 6.0 mega pixels fixada na extremidade de uma estrutura na forma de um "L" invertido para que as imagens fossem obtidas paralelamente à superfície do gramado, em mesma altura $(1,6 \mathrm{~m})$, evitando a sombra do fotógrafo, ou qualquer parte da câmera, o que proporcionou imagem digital correspondente à área, aproximadamente de $2 \mathrm{~m}^{2}$. Cada uma dessas figuras foi analisada no programa Corel Photo Paint v. 10.410, conforme metodologia de Richardson et al. (2001) que permite contar o número de pontos (pixels) de uma determinada cor. Dessa forma determinou-se a taxa de cobertura do solo pela grama (TCS) pelo método da seleção de pixels cor verde e palha.

Depois de formados, foram cortados tapetes de $2,5 \mathrm{~cm}$ de espessura, utilizando colhedora acoplada ao trator (palete) sendo determinada a quantidade de fitomassa extraída com os mesmos. Dos tapetes colhidos foram coletados quatro amostras (plugs) de $6,8 \mathrm{~cm}$ de diâmetro por parcela através de um trado amostrador (tubo de aço inox com $50 \mathrm{~cm}$ de comprimento e $8 \mathrm{~cm}$ de diâmetro afunilado na extremidade com $6,8 \mathrm{~cm}$ de diâmetro). Os "plugs" foram lavados com água destilada para retirar o solo aderido do material. Posteriormente o material coletado foi seco em estufa de circulação forçada de ar por 72 horas, na temperatura de $65^{\circ} \mathrm{C}$ e após seca foram pesadas para determinação da fitomassa seca.

Após a determinação da fitomassa seca, cada material vegetal foi moído e enviado para o Laboratório de Nutrição de Plantas da FCA para determinação da concentração de nutrientes de acordo com a metodologia de Malavolta et al. (1997). O acúmulo de nutrientes foi calculado multiplicando a fitomassa seca pela concentração de nutriente de cada parte (folhas + caules e rizomas + estolões + raízes) da grama.

Os resultados foram submetidos à análise estatística, utilizando o software "SISVAR" versão 4.2 (FERREIRA, 2003).

\section{RESULTADOS E DISCUSSÃO}

Houve aumento no total da massa das aparas com o aumento das doses de nitrogênio (Figura 1), sendo que para a maior dose aplicada $\left(600 \mathrm{~kg} \mathrm{de} \mathrm{N} \mathrm{ha}^{-1}\right)$ foi retirada da área $5.567 \mathrm{~kg} \mathrm{ha}^{-1}$ de matéria seca cortada, até o momento da colheita dos tapetes (4 meses de ciclo). Segundo Carrow et al. (2001) o N é o nutriente que mais influencia no crescimento e densidade das folhas da grama, o que justifica o resultado encontrado.

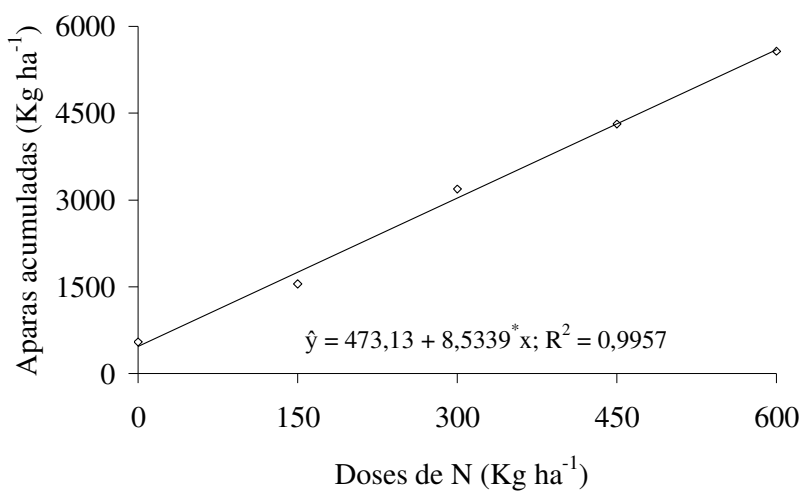

Figura 1. Acúmulo das aparas da grama Cynodon dactylon (bermuda) em função de doses de nitrogênio.

Doses maiores de $\mathrm{N}$ e maior frequência de aplicação podem reduzir o tempo de produção da grama, entretanto, doses excessivas causam crescimento acelerado e resultam em mais cortes, aumentando os custos de manutenção (QUIROGAGARZA et al., 2001).

Verifica-se na Figura 2 que houve efeito quadrático das doses de $\mathrm{N}$ para o acúmulo de fitomassa seca após a colheita dos tapetes de grama bermuda. A fitomassa seca total ajustou-se ao modelo quadrático com a dose de $405 \mathrm{~kg} \mathrm{ha}^{-1}$ proporcionando o máximo acúmulo, 11,59 $\mathrm{Mg} \mathrm{ha}^{-1}$. Para a grama esmeralda Backes et al. (2010) obtiveram acúmulo de $17,32 \mathrm{Mg} \mathrm{ha}^{-1}$ com a dose de $28 \mathrm{Mg} \mathrm{ha}^{-1}$ de lodo de esgoto. O lodo aplicado apresentava $3,2 \%$ de $\mathrm{N}$, com taxa de mineralização 
de $30 \%$ ao ano, o que corresponde a aproximadamente $269 \mathrm{~kg} \mathrm{ha}^{-1}$ de N. Godoy (2005) encontrou valor máximo de $17,15 \mathrm{Mg} \mathrm{ha}^{-1}$ de fitomassa seca total ao aplicar a dose de $600 \mathrm{~kg} \mathrm{ha}^{-1}$ de N.
Para todos os nutrientes extraídos com as aparas houve efeito linear crescente das doses de $\mathrm{N}$ (Figura 3).

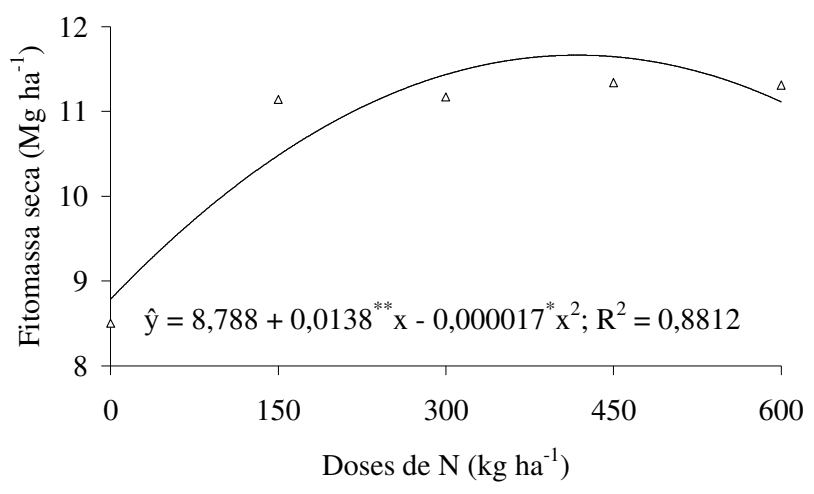

Figura 2. Fitomassa seca da grama Cynodon dactylon (bermuda) em função de doses de nitrogênio retirada com a colheita do tapete.
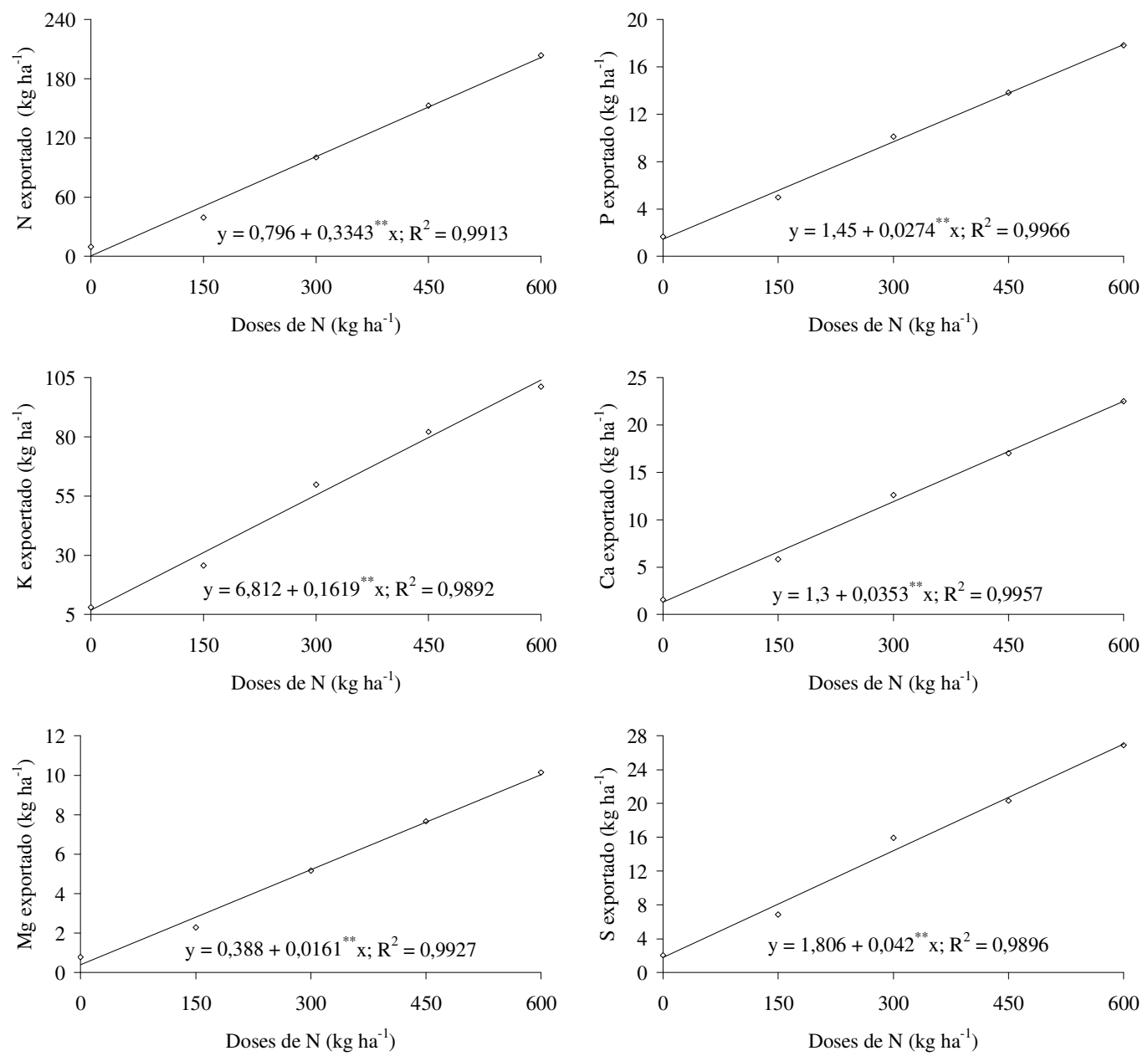

Figura 3. Extração de nitrogênio, fósforo, potássio, cálcio, magnésio e enxofre pelas retiradas das aparas, da grama Cynodon dactylon (bermuda) em função de doses de nitrogênio. 
A quantidade de $\mathrm{N}$ extraído pelas aparas variou de 9,61 na dose zero a 203,69 $\mathrm{kg} \mathrm{ha}^{-1}$ quando aplicada a dose de $600 \mathrm{~kg} \mathrm{ha}^{-1}$ de N. Por se tratar do nutriente mais exigido pela cultura, o aumento das doses de $\mathrm{N}$ proporcionou maior crescimento das folhas, aumentando assim a produção de matéria seca e consequentemente a extração de nutrientes.

Com a retirada das aparas da área de produção da grama bermuda, houve exportação de $34 \%$ do nitrogênio aplicado, quando considerada a maior dose (600 kg ha ${ }^{-1}$ ) (Figura 3). Backes et al. (2010) verificaram que com a retirada das aparas da área de produção da grama esmeralda, houve exportação de $23 \%$ do $\mathrm{N}$ disponível aplicado, quando considerada a maior dose $\left(400 \mathrm{~kg} \mathrm{ha}^{-1} \mathrm{de} \mathrm{N}\right.$ na forma de lodo de esgoto).

Para Bowman et al. (2002) o N que entra no sistema da grama como fertilizante uma das saídas a ser considerada é a remoção das aparas. Segundo Godoy e Villas Bôas (2008) a quantidade de aparas, quando retiradas do gramado, exporta, em função do teor de $\mathrm{N}$ nestas, cerca de 25 e $60 \%$ do $\mathrm{N}$ aplicado. Adeli et al. (2003) obtiveram remoção de 46 e 39\% de $\mathrm{N}$ quando aplicaram doses de 660 e $670 \mathrm{~kg} \mathrm{ha}^{-1}$ de $\mathrm{N}$, respectivamente, tendo como fonte efluente de suíno. Hummel e Waddington (1984) em três anos de estudo constataram a exportação de 46 a $59 \%$ do $\mathrm{N}$ aplicado quando as aparas foram recolhidas do gramado. Dessa forma, quando as aparas são devolvidas a área, pode ocorrer uma diminuição da adubação nitrogenada nos gramados.

A extração de $\mathrm{P}$ pelas aparas foi de 1,67 a $17,82 \mathrm{~kg} \mathrm{ha}^{-1}$ com o aumento das doses de N. De 80 $\mathrm{kg} \mathrm{ha}^{-1}$ de $\mathrm{P}_{2} \mathrm{O}_{5}\left(40 \mathrm{~kg} \mathrm{ha}^{-1}\right.$ de P) aplicado, $44 \%$ foi removido. Adeli et al. (2003) aplicando doses de 145 e $163 \mathrm{~kg} \mathrm{ha}^{-1}$ de $\mathrm{P}$ (efluente de suíno) obtiveram uma remoção de 34 e $42 \mathrm{~kg} \mathrm{ha}^{-1}$ de $\mathrm{P}$, respectivamente, correspondente a 23 e $13,4 \%$ do $\mathrm{P}$ aplicado.

A máxima extração de $\mathrm{K}$ pelas aparas da grama bermuda foi de $101,26 \mathrm{~kg} \mathrm{ha}^{-1}$ quando aplicada a dose de $600 \mathrm{~kg} \mathrm{ha}^{-1}$ de N. Considerando a quantidade de $\mathrm{K}$ adicionada, $200 \mathrm{~kg} \mathrm{ha}^{-1}$ de $\mathrm{K}_{2} \mathrm{O}$ correspondente a $165,9 \mathrm{~kg} \mathrm{ha}^{-1}$ de $\mathrm{K}, 61 \%$ do total aplicado foi removido com as aparas.

A extração de $\mathrm{Ca}$ e $\mathrm{Mg}$ pelas aparas também aumentaram com as doses de $\mathrm{N}$, chegando a 22,48 e $10,15 \mathrm{~kg} \mathrm{ha}^{-1}$, respectivamente, com a maior dose aplicada. A extração de $\mathrm{S}$ variou de 2 a $27 \mathrm{~kg} \mathrm{ha}^{-1}$ com as doses de $\mathrm{N}$.

$\mathrm{Na}$ Figura 4 estão representadas as regressões do acúmulo de $\mathrm{N}, \mathrm{P}, \mathrm{K}, \mathrm{Ca}, \mathrm{Mg}$ e $\mathrm{S}$ na grama Cynodon dactylon (bermuda) em função de doses de nitrogênio. A quantidade de $\mathrm{N}$ acumulada na grama aumentou linearmente com as doses de $\mathrm{N}$.
A máxima extração de $\mathrm{N}$ pela retirada do tapete foi de 184,12 $\mathrm{kg} \mathrm{ha}^{-1}$. Godoy (2005) aplicando até 600 $\mathrm{kg} \mathrm{ha}^{-1}$ de N na grama esmeralda e Santo agostinho verificou que a quantidade desse nutriente acumulado pelas gramas foi de $242 \mathrm{~kg} \mathrm{ha}^{-1}$ e $104 \mathrm{~kg}$ $\mathrm{ha}^{-1}$, respectivamente.

O total de nitrogênio extraído variou de 77 $\mathrm{kg} \mathrm{ha}^{-1}$ na dose zero a $388 \mathrm{~kg} \mathrm{ha}^{-1}$ quando aplicada a dose de $600 \mathrm{~kg}$ de $\mathrm{N} \mathrm{ha}^{-1}$. Das doses de $\mathrm{N}$ estudadas $150,300,450$ e $600 \mathrm{~kg} \mathrm{ha}^{-1}$, houve recuperação pelas plantas do total aplicado de aproximadamente 97, 70, 66 e 65\%, respectivamente. Este aproveitamento do fertilizante nitrogenado pode ser considerado alto, pois conforme Mattos Junior et al. (2002) a eficiência pode ser da ordem de $44 \%$ dependendo da fonte do fertilizante e as condições da aplicação. Osborne et al. (1999) verificaram que a recuperação do $\mathrm{N}$ pela grama bermuda diminuía com a aplicação de doses crescentes de $\mathrm{N}$.

Para a quantidade de $\mathrm{P}$ extraída com a retirada do tapete verifica-se que a maior dose de $\mathrm{N}$ aplicada proporcionou menor acúmulo desse nutriente nas partes da planta. Possivelmente as grandes quantidades de $\mathrm{N}$ forçaram o crescimento da parte aérea em detrimento do sistema radicular. A máxima extração de $\mathrm{P}$ pela retirada do tapete foi de $22 \mathrm{~kg} \mathrm{ha}^{-1}$ com a dose de $196 \mathrm{~kg} \mathrm{ha}^{-1}$ de $\mathrm{N}$, de acordo com a equação ajustada. $\mathrm{O} P$ transportado com o tapete, considerando planta e solo, pode melhorar o pegamento, a recuperação e a qualidade dos gramados quando o tapete colhido é transplantado (VIETOR et al., 2004).

A extração de $\mathrm{K}$ com a retirada do tapete da grama bermuda também se ajustou ao modelo quadrático, onde a máxima extração $\left(146 \mathrm{~kg} \mathrm{ha}^{-1} \mathrm{de}\right.$ K) foi obtida com a dose de $450 \mathrm{~kg} \mathrm{ha}^{-1}$ de $\mathrm{N}$, de acordo com a equação, $45 \mathrm{~kg} \mathrm{ha}^{-1}$ a mais que a dose que proporcionou maior acumulo de fitomassa seca da planta. A quantidade total de $\mathrm{K}$ extraída pela grama bermuda quando aplicada a dose de $600 \mathrm{~kg}$ $\mathrm{ha}^{-1}$ de $\mathrm{N}$ foi de $229,76 \mathrm{~kg} \mathrm{ha}^{-1}$. Vale ressaltar que a dose de potássio aplicada foi de apenas $200 \mathrm{~kg} \mathrm{ha}^{-1}$ de $\mathrm{K}_{2} \mathrm{O}$, sendo que a quantidade extraída foi maior. Possivelmente a grama utilizou a quantidade de $\mathrm{K}$ no solo $\left(1,6 \mathrm{mmol}_{\mathrm{c}} \mathrm{dm}^{-3}\right)$ e a quantidade armazenada nos rizomas que ficaram no solo após o corte do tapete anterior. Por ser o segundo nutriente mais extraído pela grama bermuda, a reposição de potássio no solo através da adubação é de grande importância, pois a maior parte deste nutriente utilizado pela planta é exportada da área de produção com o corte do tapete. Godoy et al. (2007) verificaram que o potássio não influenciou $o$ crescimento da grama e nem a velocidade de fechamento do tapete, no entanto o nível de $\mathrm{K}$ na 
planta influenciou outras características da planta como a perda da água por transpiração.
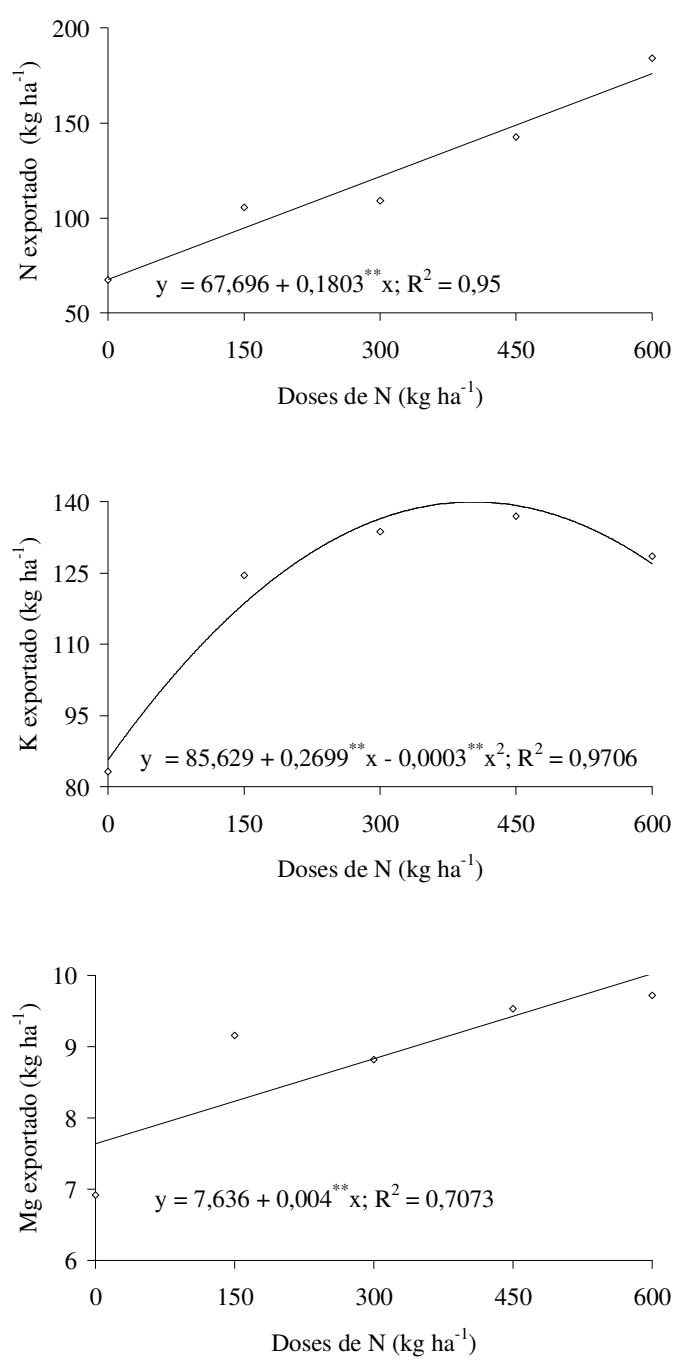
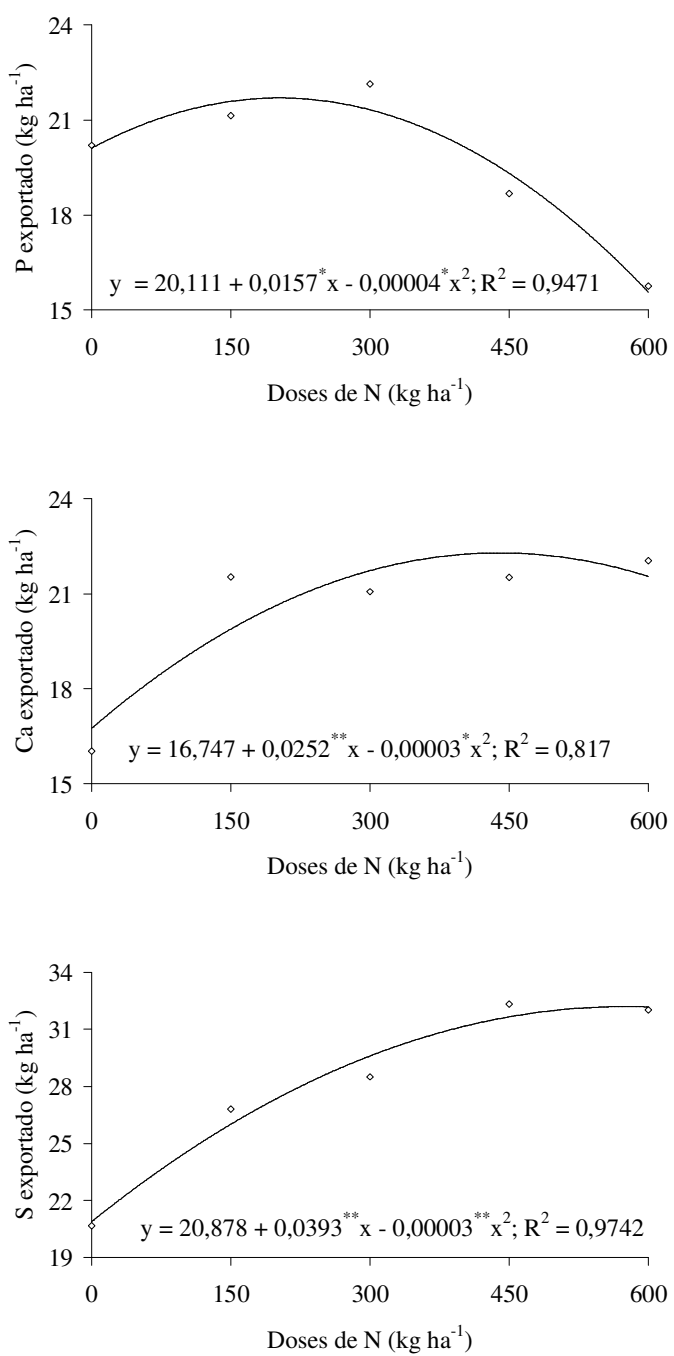

Figura 4. Exportação de nitrogênio, fósforo, potássio, cálcio, magnésio e enxofre pela grama Cynodon dactylon (bermuda) em função de doses de nitrogênio.

Os máximos valores de $\mathrm{Ca}$ e $\mathrm{Mg}$ acumulados e removidos pela grama bermuda com o tapete, de acordo com as equações ajustadas, foram de 22 e $9,7 \mathrm{~kg} \mathrm{ha}^{-1}$ com as doses de 420 e $600 \mathrm{~kg} \mathrm{ha}^{-}$ 1. Ao considerar as quantidades desses nutrientes extraídos pela retirada dos tapetes e das aparas têmse valores de 44,52 $\mathrm{kg} \mathrm{ha}^{-1}$ de Ca e 19,87 $\mathrm{kg} \mathrm{ha}^{-1}$ de $\mathrm{Mg}$.

Para a quantidade de $\mathrm{S}$ exportada com o tapete, embora tenha sido ajustado o modelo quadrático em função das doses de $\mathrm{N}$, a máxima quantidade foi atingida, de acordo com a equação, acima das doses estudadas. Pode-se considerar que a exportação de $\mathrm{S}$ aumentou com as doses de $\mathrm{N}$ até $600 \mathrm{~kg} \mathrm{ha}^{-1}$. A extração total variou de 23 a $59 \mathrm{~kg}$ $\mathrm{ha}^{-1} \mathrm{com}$ as doses de N. Considerando os valores de extração e a remoção da camada superficial do solo onde há maior concentração de matéria orgânica, fonte de $\mathrm{S}$, deve-se atentar para a reposição desse nutriente nos cultivos subsequentes.

A quantidade total de nutrientes extraídos pela grama pode dar uma ideia da quantidade a ser reposta no próximo ciclo. Ao relacionar a taxa de cobertura do solo pela grama, que é um indicativo do fechamento do tapete, com a quantidade de nutrientes extraídos pelas aparas e pela planta dentro de cada dose de $\mathrm{N}$ aplicada, verifica-se a possibilidade de definir doses necessárias para a obtenção de uma taxa de cobertura de $100 \%$ (Figura 5). Para o N a dose é de aproximadamente $219,5 \mathrm{~kg} \mathrm{ha}^{-1}$, visto que esta foi a quantidade total deste nutriente exportado pela 
grama que permitiu $100 \%$ de cobertura do solo. Para os demais macronutrientes, as quantidades necessárias para o fechamento do tapete de grama bermuda em aproximadamente 4 meses são: 27; 174,1; 31,8; 13,4; e 39,9 $\mathrm{kg} \mathrm{ha}^{-1}$ de P, K, Ca, Mg e
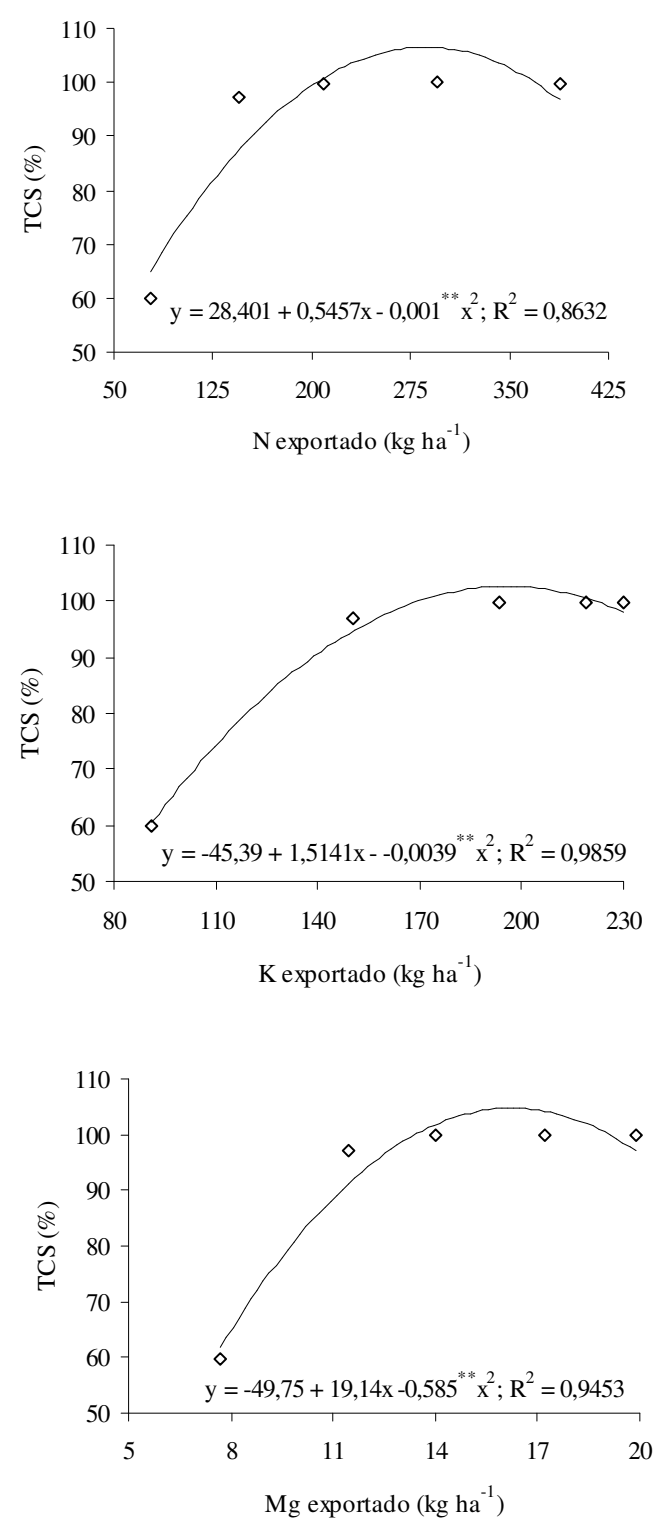

S, respectivamente. Vale ressaltar que não está sendo consideradas às perdas que existe no sistema, que dependerão das condições climáticas, tipos de solos e fontes utilizadas.
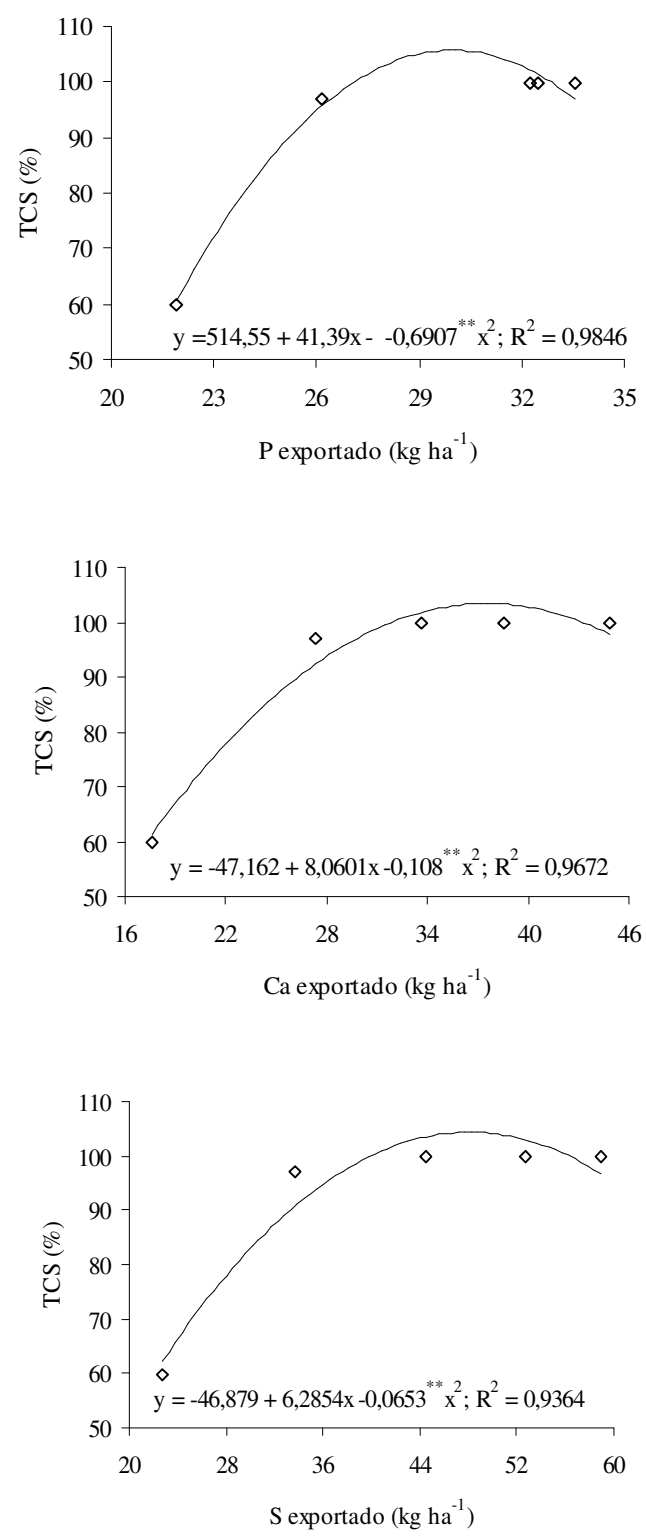

Figura 5. Taxa de cobertura do solo em função da quantidade de nutrientes exportados pela grama Cynodon dactylon (bermuda).

\section{CONCLUSÕES}

Com o aplicação das doses de $\mathrm{N}$ obteve-se aumentos lineares da extração de todos os nutrientes pelas aparas.

As doses de 196, 450 e $420 \mathrm{~kg} \mathrm{ha}^{-1}$ de $\mathrm{N}$ proporcionaram a máxima extração e exportação de
$\mathrm{P}, \mathrm{K}$ e $\mathrm{Ca}$, respectivamente, em função da retirada dos tapetes. Para $\mathrm{N}, \mathrm{Mg}$ e $\mathrm{S}$ os maiores valores foram obtidos com a aplicação de $600 \mathrm{~kg} \mathrm{ha}^{-1}$.

A máxima extração de nutrientes pela grama bermuda foi de $388,40,247,44,18$ e $59 \mathrm{~kg} \mathrm{ha}^{-1}$ de $\mathrm{N}, \mathrm{P}, \mathrm{K}, \mathrm{Ca}, \mathrm{Mg}$ e S, respectivamente. 
ABSTRACT: Nitrogen provides the greatest answers in grass growth. The objective of this work was to evaluate the total extraction of nutrients by the bermudagrass due to nitrogen levels. The experiment was conduced in a grass property, located in Capela do Alto - SP. The experimental design was a randomized blocks, with five treatments and four replications. The treatments consisted of five $\mathrm{N}$ doses: 0, 150, 300, 450 and $600 \mathrm{~kg} \mathrm{ha}^{-1}$. After each grass cut were collected clippings and determined dry matter and macronutrients content. After sod harvest, it was determined the dry matter extracted with the withdrawal of it and the nutrients concentration. The amounts of macronutrients were calculated by the product of dry weight by their concentration. With the withdrawal of clippings cut during the cycle there was a great extraction of nutrients, 204; 18;101; 22; 10 and $27 \mathrm{~kg} \mathrm{ha}^{-1}$ for N, P, K, Ca, Mg e S, respectively. The amount of nutrients needed to promote $100 \%$ of grass soil coverage are $219.5,27,174.1,31.8,13.4$ and $39.9 \mathrm{~kg} \mathrm{ha}^{-1}$, of $\mathrm{N}, \mathrm{P}, \mathrm{K}, \mathrm{Ca}, \mathrm{Mg}$ and $\mathrm{S}$, respectively.

KEYWORDS: Cynodon dactylon. Fertilization. Clippings. Extraction.

\section{REFERÊNCIAS}

ADELI, A.; VARCO, J. J.; ROWE, E. Swine effluent irrigation rate and timing effects on bermudagrass growth, nitrogen and phosphorus utilization, and residual soil nitrogen. Journal of Environmental Quality, Madison, v. 32, p. 681-686, 2003. http://dx.doi.org/10.2134/jeq2003.0681

BACKES, C. LIMA, C. P.; GODOY, L. J. G.; SANTOS, A. J. M.; VILLAS BÔAS, R. L.; BÜLL, L. T. Produção, acúmulo e exportação de nutrientes em grama esmeralda adubada com lodo de esgoto. Bragantia, Campinas, v. 69, n. 2, p. 413-422, 2010. http://dx.doi.org/10.1590/S0006-87052010000200021

BACKES, C.; LIMA, C. P. Uso de lodo de esgoto e ajifer na produção de gramas. In: VILLAS BÔAS, R. L.; GODOY, L. J. G.; LIMA, C. P.; BACKES, C. Tópicos atuais em gramados. Botucatu: Faculdade de Ciências Agronômicas, UNESP, 2008. p. 20-36.

BOWMAN, D. C., CHERNEY, C. T., RUFTY JUNIOR, T. W. Fate and transport of nitrogen applied to six warm-season turfgrasses. Crop Science, v. 42, p. 833-841, 2002. http://dx.doi.org/10.2135/cropsci2002.0833

CARROW, R. N.; WADDINGTON, D. V.; RIEKE, P. E. Turfgrass soil fertility and chemical problem: assessment and management. Chelsea, MI: Ann Arbor Press, 2001, 400 p.

CHRISTIANS, N. E. Fundamental of turfgrass management, Chelsea, MI: Arbor Press, 1998, 301p.

EXNER, M. E, BURBACH, M. E., WATTS, D. G., SHERMAN, R. C., SPALDING, R F. Deep nitrate movement in the unsatured zone of a simulated urban lawns. Journal of Environmental Quality, Madison, v. 20, p. 658-662, 1991. http://dx.doi.org/10.2134/jeq1991.00472425002000030025x

FERREIRA, D. F. Sisvar versão 4.2. DEX/UFLA, 2003.

GODOY, L. J. G.; VILLAS BÔAS, R. L. Calagem e adubação para gramados: Como potencializar a produção e a manutenção. In: VILLAS BÔAS, R. L; GODOY, L. J. G.; LIMA, C. P.; BACKES, C. Tópicos atuais em gramados, Botucatu: UNESP, 2008, cap.1 p. 2-19.

GODOY, L. J. G.; VILLAS BÔAS, R. L.; BACKES, C.; LIMA, C. P. Doses de nitrogênio e potássio na produção de grama esmeralda. Ciência e Agrotecnologia, Lavras, v. 31, n. 5, p. 1326-1332, 2007.

http://dx.doi.org/10.2136/sssaj1984.03615995004800010035x

GODOY, L. J. G. Adubação nitrogenada para produção de tapetes de grama santo agostinho e esmeralda. 2005, 106p. Tese (Doutorado em Agronomia/Agricultura) - Faculdade de Ciências Agronômicas, UNESP, Botucatu, SP, 2005. 
GODOY, L. J. G.; VILLAS BÔAS, R. L. Nutrição e adubação para gramados. In: SIMPÓSIO SOBRE GRAMADOS, 1, 2003, Botucatu. Produção, implantação e manutenção: Anais. Botucatu: Departamento de Recursos Naturais, Faculdade de Ciências Agronômicas, Universidade Estadual Paulista, 2003. CD-ROM.

HUMMEL, N. W.; WADDINGTON, D. V. Súlfur-coated urea for turfgrass fertilization. Soil Science Society of America Journal, v. 48, p. 191-195, 1984. http://dx.doi.org/10.2136/sssaj1984.03615995004800010035x

MALAVOLTA, E.; VITTI, G. C.; OLIVEIRA, S. A. Avaliação do estado nutricional das plantas: princípios e aplicações, 2ed. Piracicaba: POTAFOS (Associação brasileira de pesquisa da potassa e do fosfato), 1997. 317p.

MATTOS JUNIOR, D. de; CANTARELA, H.; QUAGGIO, J. A. Perdas por volatilização do nitrogênio fertilizante aplicado em pomares de citros. Laranja, Cordeirópolis, v. 23, p. 263-270, 2002.

OSBORNE, S. L.; WILLIAM, R. R.; GORDON, V. J.; ROGERS, J. L. Bermudagrass response to high nitrogen rates, source, and season of application. Agronomy Journal, Madison, v. 91, p. 438-444, 1999. http://dx.doi.org/10.2134/agronj1999.00021962009100030013x

QUIROGA-GARZA, H. M., PICCHIONI, G. A., REMMENGA, M. D. Bermudagrass fertilized with slowrelease nitrogen sources. I. Nitrogen Uptake and potential leaching losses. Journal of Environmental Quality, Madison, v. 30, p. 440-448, 2001. http://dx.doi.org/10.2134/jeq2001.302440x

RICHARDSON, M. D., KARCHER, D. E., PURCELL, L. C. Quantifying turfgrass cover using digital image analysis. Crop Science, Madison, v. 41, p. 1884-1888, 2001. http://dx.doi.org/10.2135/cropsci2001.1884

VIETOR, D. M.; PROVIN, T. L.; WHITE, R. H.; MUNSTER, C. L. Runoff losses of phosphorus and nitrogen imported in sod or composted manure for turf establishment. Journal of Environmental Quality, Madison, v. 33, p. 358-366, 2004. http://dx.doi.org/10.2134/jeq2004.3580 